\title{
https://helda.helsinki.fi
}

Injection-Locked Single-Mode VCSEL for Orthogonal

Multiplexing and Amplitude Noise Suppression

\section{Chipouline, Arkadi}

IEEE

2017

Chipouline , A , Lyubopytov , V S , Malekizandi , M , von Lerber , T , Lassas , M \& Küppers , F 2017 , Injection-Locked Single-Mode VCSEL for Orthogonal Multiplexing and Amplitude Noise Suppression . in 2017 CONFERENCE ON LASERS AND ELECTRO-OPTICS EUROPE \& EUROPEAN QUANTUM ELECTRONICS CONFERENCE (CLEO/EUROPE-EQEC) . IEEE , Conference on Lasers and Electro-Optics/Europe and the European Quantum Electronics Conference , Munich , Germany , 25/06/2017 . https://doi.org/10.1109/CLEOE-EQE

http://hdl.handle.net/10138/311068

https://doi.org/10.1109/CLEOE-EQEC.2017.8086943

unspecified

acceptedVersion

Downloaded from Helda, University of Helsinki institutional repository.

This is an electronic reprint of the original article.

This reprint may differ from the original in pagination and typographic detail.

Please cite the original version. 


\title{
Injection-Locked Single-Mode VCSEL for Orthogonal Multiplexing and Amplitude Noise Suppression
}

\author{
Arkadi Chipouline ${ }^{1}$, Vladimir S. Lyubopytov ${ }^{1,2,3}$, Mohammadreza Malekizandi, Tuomo von Lerber ${ }^{4}$, Matti \\ Lassas $^{4}$, Franko Küppers ${ }^{1}$ \\ ${ }^{1}$ Institute for Microwave Engineering and Photonics, Technische Universität Darmstadt, Merckstr. 25, 64283 Darmstadt, Germany \\ ${ }^{2}$ Dpt. Photonics Engineering, Technical University of Denmark (DTU), Ørsteds Plads 343, 2800 Kgs. Lyngby, Denmark \\ ${ }^{3}$ Telecommunication Systems Dept., Ufa State Aviation Technical University, 12 K. Marx St., 450000 Ufa, Russia \\ ${ }^{4}$ Department of Mathematics and Statistics, University of Helsinki, P.O. Box 68 (Gustaf Hällströmin katu 2b) FI-00014 Helsinki, Finland
}

It has been shown earlier, that the injection locked semiconductor lasers enable effective amplitude noise suppression [1] and makes possible an extra level of signal multiplexing - orthogonal modulation [2], where DPSK and ASK NRZ channels propagate at the same wavelength [3]. In our work we use an injection-locked $1550 \mathrm{~nm}$ VCSEL as a slave laser providing separation of amplitude and phase modulations, carrying independent information flows. To validate the possibility of phase modulation extraction by an injection-locked VCSEL, an experimental setup shown in Fig. 1 has been built.

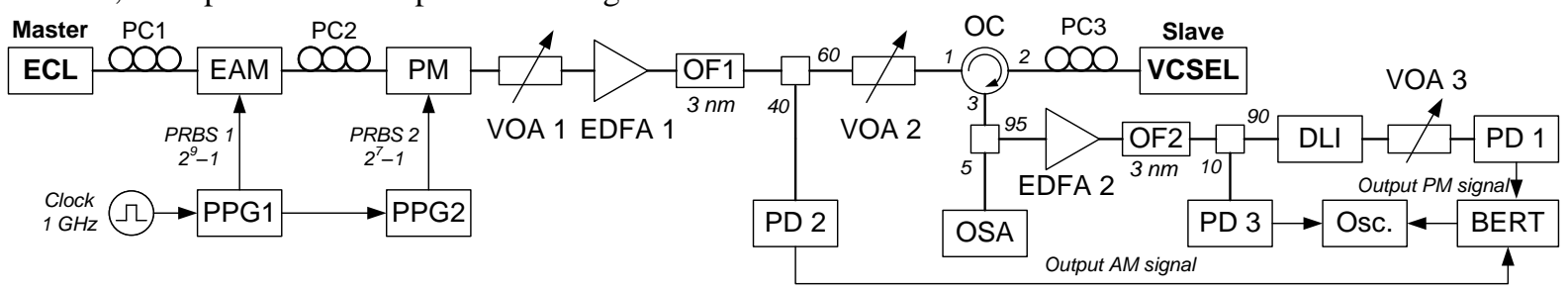

Fig. 1. Scheme of the experimental setup (ECL - external cavity lase; PC - polarization controller; EAM - electro-absorption modulator; PM - phase modulator; VOA - variable optical attenuator; OF - bandpass optical filter; OC - optical circulator; PD - p-i-n photodiode; DLI delay line interferometer; OSA - optical spectrum analyzer; Osc. - digitizing oscilloscope).

The obtained results shown in Fig. 2(a) demonstrate the suppression of the amplitude modulation (AM) in an optical signal rectified by the VCSEL. At the value of AM Extinction Ratio (ER) $7.8 \mathrm{~dB}$, where eye diagram of the detected DBPSK-signal tends to be closed, employment of the proposed approach provides gain of $4.75 \mathrm{~dB}$ in diminishing ER, which allows keeping the eye open. Fig. 2(b) shows BER vs. AM ER dependences in the phase modulated channel. As follows from these curves, utilization of the injection-locked VCSEL provides significant improvement of the transmission reliability for DBPSK signal component, BER improvement of 8 orders can be achieved.

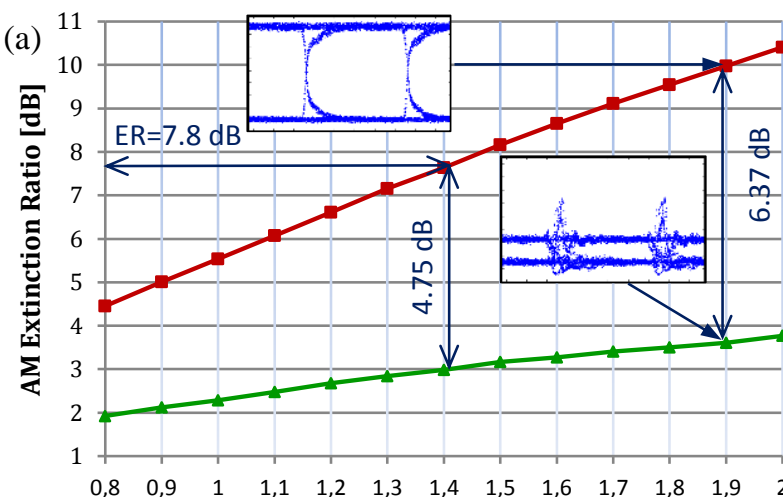

$\rightarrow$ ER before VCSEL Modulating Voltage [V]

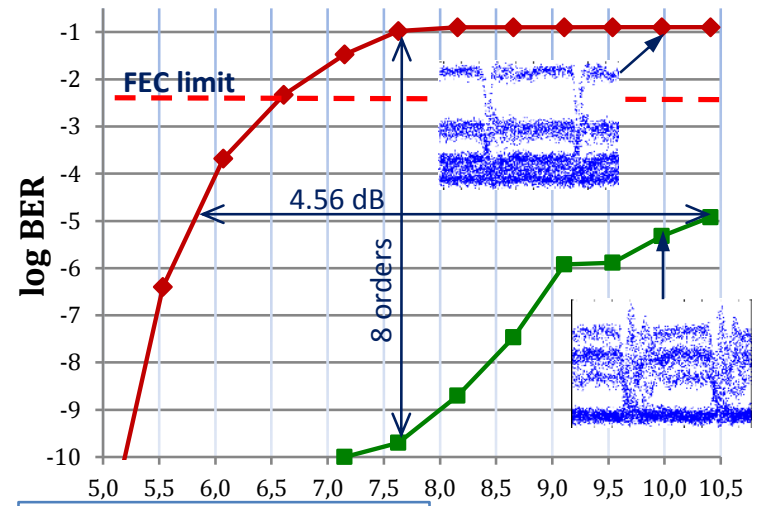

$\multimap$ PM component, reference $\longrightarrow$ PM component, with VCSEL

AM Extinction Ratio [dB]

Fig. 2. (a) Extinction ratio of amplitude modulation measured at the input (red) and the output (green) of injection-locked VCSEL; (b) BER vs. ER of AM for the DBPSK channel before (red) and after (green) phase rectification using VCSEL.

\section{References}

[1] A. Fragkos, A. Bogris, D. Syvridis, and R. Phelan, "Colorless Regenerative Amplification of Constant Envelope Phase-Modulated Optical Signals Based on Injection-Locked Fabry-Pérot Lasers,” IEEE Photon. Technol. Lett. 24, 28 (2012).

[2] Y. Zhang, N. Deng, C.-K. Chan, and L.-K. Chen, "A Multicast WDM-PON Architecture Using DPSK/NRZ Orthogonal Modulation", IEEE Photon. Technol. Lett. 20, 1479 (2008).

[3] A. Fragkos, A. Bogris, and D. Syvridis, "Spectrally efficient and High Extinction Ratio DPSK/ASK Orthogonal Modulation Schemes Based on Injection Locking Limiting Amplifiers", in ECOC Technical Digest, (OSA, 2012), paper P3.04. 